\title{
Modelling and Simulation of All-Electric Machines and Renewable Electric Power Systems in Agricultural Operations
}

\author{
Felix Klabunde ${ }^{1 *}$, Christian Reinhold ${ }^{1}$, Bernd Engel ${ }^{1}$ \\ 1 elenia Institute for High Voltage Technology and Power Systems, Technische Universität Braunschweig, \\ Schleinitzstrasse 23, 38106 Braunschweig, Germany; ${ }^{*}$.klabunde@tu-braunschweig.de
}

\begin{abstract}
Today's operation of agricultural machines is still characterised by the use of fossil fuels. In the future, all-electric agricultural machines can be used, whose energy requirements must be covered by local renewable energies or the power grid. The occurrence of limit value violations in the power grid can slow down and hinder this change in agricultural operations. For this reason, this paper describes the modelling and simulation of allelectric agricultural machines, renewable energy systems and rural power grids and the evaluation of suitable energy supply strategies for the machines and needed investments in the power grid.
\end{abstract}

\section{Introduction}

The restructuring of the German energy system in the context of the Energiewende requires the interaction and commitment of private and commercial stakeholders. As one of the main players in decentralized energy production, today's agriculture already has a special role in the Energiewende. In addition to the widespread photovoltaic plants, agriculturally operated biogas plants can be used to provide weatherindependent electrical and thermal power. The combination of different generation and storage systems leads to a variety of energy structures with different technical and economic potential. In combination with new electricity applications in agriculture, such as all-electric agricultural machines, these energy structures have the potential to make agriculture sustainable in the long term. To determine the technical-economic potential and to derive suitable recommendations for action for the involved stakeholders, it is necessary to carry out holistic modelling and simulation of the involved technologies. Therefore, this paper describes the modelling and simulation of agricultural influenced energy sys- tems and power grids with a focus on all-electric agricultural machines. In a simulation of different scenarios, suitable energy supply strategies are derived.

\section{All-electric agricultural machines}

More and more manufacturers of agricultural machinery have turned their attention to all-electric agricultural machines in recent years. Given the further development of power electronics and electric motors, as well as new requirements in efficiency and environmental protection, a future use of all-electric agricultural machines is realistic and comprehensible. For many processes in field cultivation, there are currently only prototypes and concepts and no marketready products, which is why the modelling approach of all-electric agricultural machines, as shown in Figure 1 , is based on empirical values and consumption profiles of diesel-powered agricultural machines. The

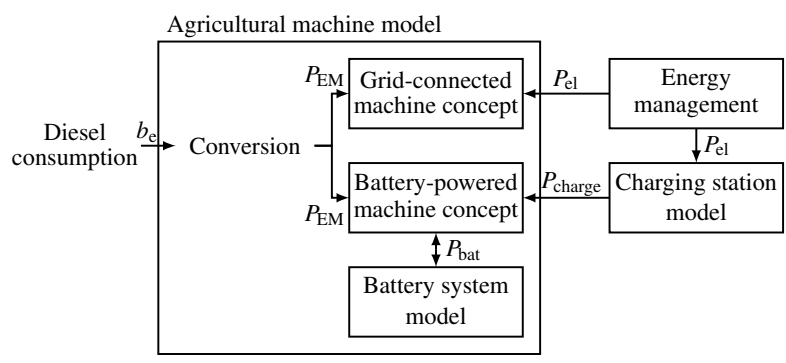

Figure 1: Modelling approach for the all-electric agricultural machines

diesel consumption profiles $b_{e}$ are converted to electrical power values $P_{E M}$, which represent the power requirement of the electric drive train. These electrical consumption profiles serve as input data for the two 
modelled machine concepts: the battery-powered agricultural machine and the grid-connected agricultural machine. The battery-powered agricultural machine is recharged by the charging station with the charging power $P_{\text {charge }}$. The charging station as well as the gridconnected agricultural machine are connected to the energy management system via their electrical power consumption $P_{\mathrm{el}}$. The conversion process as well as both machine concepts are explained in more detail below.

\subsection{Conversion of the diesel consumption profiles}

The diesel consumption profiles used in this paper were created in the EkoTech research project [1] and represent a typical agricultural process chain in field cultivation. The process chain includes the agricultural processes soil tillage, sowing, plant protection, fertilisation and harvesting. While three agricultural machines are used simultaneously for harvesting (harvester and two tractors for transporting the harvest), only one agricultural machine is used at a time for the other processes. The use of diesel consumption profiles offers the advantage of using both simulated consumption profiles as well as measured consumption profiles. By using time series instead of static data, the varying power requirements of the individual processes can be realistically represented and process-dependent statements can be made regarding the machine concept to be used and the necessary parameterisation of the agricultural machine. The conversion to an electric power profile is done by using the calorific value of diesel $H_{i}$ and overall efficiency of the diesel-powered drive train $\eta_{\mathrm{CM}}$ with $P_{E M}$ representing the power consumption of the electric drive train and $b_{e}$ representing the diesel consumption rate:

$$
P_{E M}=b_{e} \cdot H_{i} \cdot \eta_{\mathrm{CM}}
$$

With the calorific value of diesel of $9.86 \mathrm{kWh} / \mathrm{l}$ and an assumed static efficiency of the diesel-powered drive train of $30 \%$, the electric motor output, shown in Figure 2 for the process soil tillage, is obtained.

Depending on the agricultural process, the energy and power requirements of the agricultural machines vary greatly. Particularly in field cultivation, many processes are associated with a high energy input. Machines used for soil tillage, sowing and as harvester in harvesting have a high energy consumption of up to 1 MWh per day, while other processes have a comparatively low energy consumption (e.g. the resulting elec-

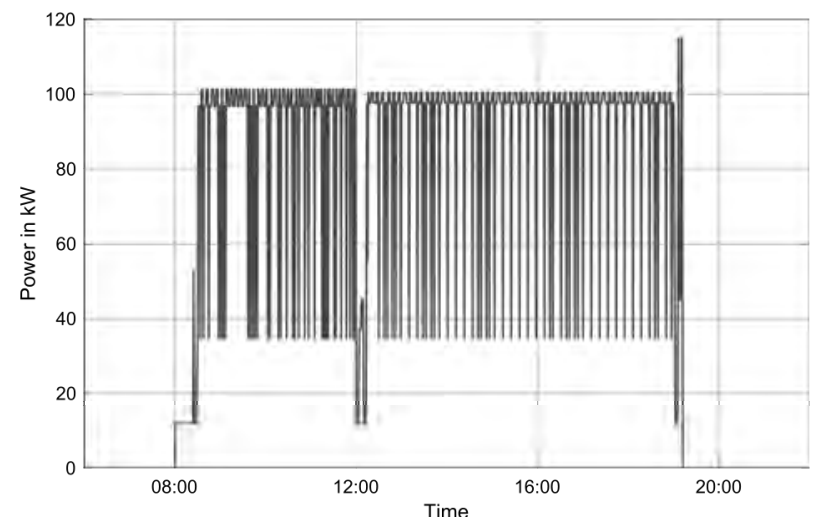

Figure 2: Resulting power consumption $P_{\mathrm{EM}}$ of the electric drive train during soil tillage

trical energy consumption for one tractor for transporting the harvest is $115 \mathrm{kWh}$ per day). Due to the different requirements it is essential to consider different machine concepts with different parameterization for allelectric agricultural machines.

\subsection{Battery-powered agricultural machine}

Battery-powered agricultural machines draw their energy from a battery system, which can be installed in the machine or as exchangeable front/back weight. The advantage of the battery-powered concept lies in its unlimited mobility and the possibility of bidirectional charging.

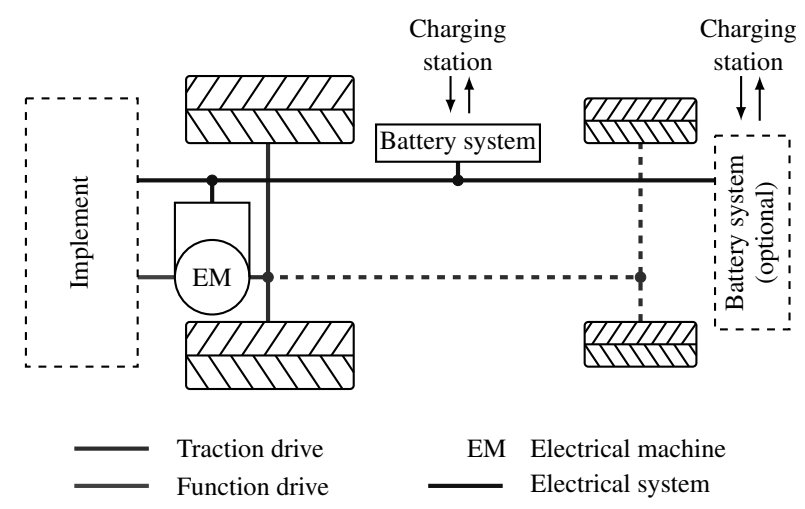

Figure 3: Possible machine concept of a battery-powered agricultural machine

The battery-powered agricultural machine is modelled by a battery system which is discharged by the specified electrical consumption profile and recharged by a model of a charging station. The presence of the agri- 
cultural machine and the maximum possible recharging time at the charging station is determined by the power consumption of the electric drive train $P_{\mathrm{EM}}$. If no power is needed $\left(P_{\mathrm{EM}}=0\right)$ it is assumed for simplification that the agricultural machine is at the charging station and has the possibility of recharging at the charging station's full nominal power. The presence of the agricultural machine at the charging station is described by the parameter appearance:

$$
P_{\mathrm{EM}}\left\{\begin{array}{l}
>0 \rightarrow \text { appearance }=0 \\
=0 \rightarrow \text { appearance }=1
\end{array}\right.
$$

The charging power at the charging station $P_{\text {charge }}$ is calculated depending on the chosen charging strategy (Charging with maximum power, Charging with minimum power) and the maximum charging power of the battery system:

$$
P_{\text {charge }}=\min \left\{\begin{array}{l}
P_{\text {bat, charge, } \text { max }} \\
P_{\text {charge, }, \text { strategy }}
\end{array}\right.
$$

$P_{\text {bat,charge,max }}$ is the maximum charging power of the battery system and $P_{\text {charge,strategy }}$ is the charging power set by the charging strategy. $P_{\text {bat,charge,max }}$ is calculated depending on the state-of-charge of the battery and is based on typical battery charging profiles. In the event that the actual state-of-charge is smaller than the stateof-charge at cut-off voltage, the charging power is calculated using the following equation:

$$
P_{\text {bat,charge,max }}=\frac{C \cdot E_{\text {bat,nom }}}{\eta_{\text {bat,charge }}}
$$

$C$ is the charging/discharging rate, $E_{\mathrm{bat}, \text { nom }}$ is the nominal battery capacity, $E_{\text {bat }}$ is the available battery capacity and $\eta_{\text {bat,charge }}$ is the charging efficiency of the battery system. If the battery voltage reaches the cut-off voltage, the charging current is reduced at constant battery voltage, resulting in a reduced charging power. This effect is implemented by adjusting equation 4 :

$$
P_{\text {bat,charge,max }}=\frac{C \cdot E_{\text {bat,nom }}}{\eta_{\text {bat,charge }}} \cdot\left(\frac{\mathrm{SOC}_{\max }-\mathrm{SOC}_{\text {max }}-\mathrm{SOC}_{\mathrm{cov}}}{\mathrm{SOC}_{\text {a }}}\right)
$$

SOC is the available state-of-charge, $\mathrm{SOC}_{\max }$ is the maximum state-of-charge and $\mathrm{SOC}_{\mathrm{cov}}$ is the state-ofcharge at cut-off voltage.

In the case of the loading strategy Charging with maximum power, the agricultural machine is reloaded with the nomimal charging power of the charging station $P_{\text {charge,nom }}$ after completion of the field cultivation:

$$
P_{\text {charge,strategy }}=P_{\text {charge, } \max }=P_{\text {charge,nom }}
$$

This charging strategy enables the agricultural machine to be recharged quickly, reducing the required idle time of the agricultural machine and increasing the potential operating time. The second charging strategy, Charging with minimum power, calculates the minimum charging power as a function of the total idle time $T_{\text {appearance }}$ as shown in the following equations and Figure 4.

$$
\begin{aligned}
E_{\mathrm{bat}, \mathrm{dest}} & =E_{\mathrm{bat}, \mathrm{nom}}-E_{\mathrm{bat}} \\
P_{\text {charge,strategy }} & =P_{\text {charge,min }}=\frac{E_{\mathrm{bat}, \mathrm{dest}}}{T_{\text {appearance }} \cdot \eta_{\text {charge }}}
\end{aligned}
$$

$E_{\text {bat,dest }}$ is the required battery capacity to be recharged, $E_{\text {bat }}$ is the available battery capacity and $P_{\text {charge,min }}$ is the minimum charging power. This charging strategy is dependent on the next operating time of the agricultural machine and potentially reduces load peaks by recharging evenly over the entire idle time of the agricultural machine.

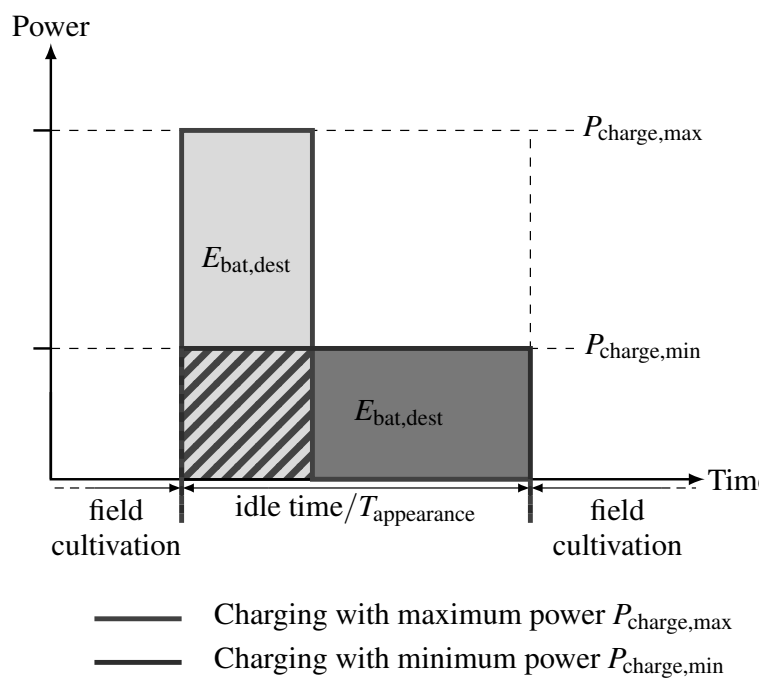

Figure 4: Influence of the charging strategies on charging power and time

For the discharge power of the battery system, it is assumed for simplification that the power consumption $P_{\mathrm{EM}}$ can be covered at any time. This assumption is sufficient, as it can be assumed that only agricultural machines that can provide the required electrical power are used. 


\subsection{Grid-connected agricultural machine}

Grid-connected agricultural machines are continuously supplied with energy via a power cable and do not have their own energy storage. Higher theoretical engine power is advantageous than with battery-powered agricultural machines, but mobility is restricted due to the cable, which is why this concept is not suitable for every agricultural process. The concept is particularly suitable for the power-intensive soil tillage and for the harvester in harvesting. In contrast to the battery-powered agricultural machine, the engine power $P_{\mathrm{EM}}$ is directly transmitted as output power $P_{\mathrm{el}}$ to the energy management.

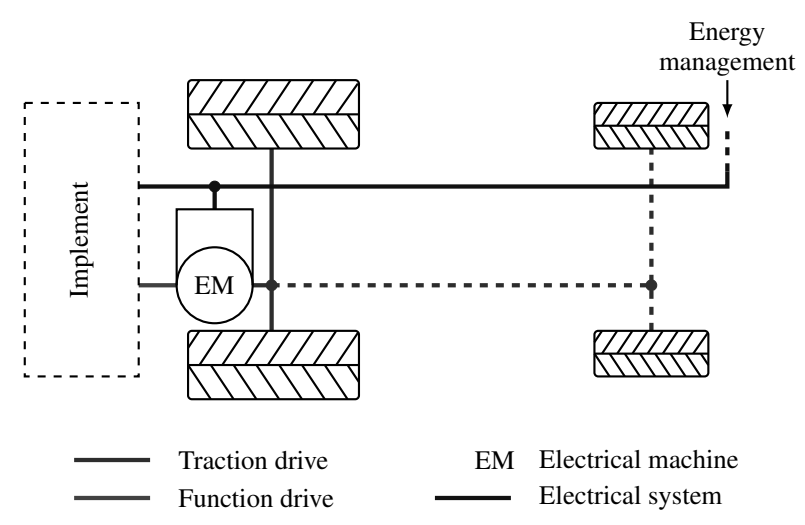

Figure 5: Machine concept of a grid-connected agricultural machine

\section{Modelling of the renewable electric power system}

All-electric agricultural machines can be supplied with energy from renewable energy plants operated by agricultural operations or from the power grid. To assess the effects of the integration of these machines and to derive suitable energy supply concepts, the modelling of the plants under consideration is necessary. In the following, the modelling of the photovoltaic plant, wind power plant and biogas plant as considered renewable energies, as well as the energy management and power grid, is briefly explained.

\subsection{Renewable Energies}

The photovoltaic model builds on the work already done in [2] and is based on a physics-based modelling approach. Weather data (solar radiation, solar azimuth, solar altitude, outdoor temperature and cloud cover) from the test reference year of the german weather service [3] and serve as input data.

A data-based modelling approach as shown in Figure 6 , is chosen for the wind turbine model, in which the generation capacity is calculated based on weather data from [4] and wind power curves from product data sheets of wind turbine manufacturers (e.g. [5])

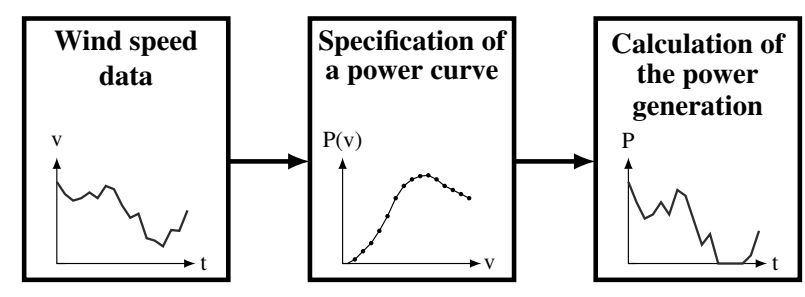

Figure 6: Data-driven modelling approach of the wind power plant

The biogas plant is modelled in a simplified way using the load profile E0 of E-Control (austrian government regulator for electricity and gas) [6]. This simplification is possible if biogas plants are operated at constant generation capacity without a flexilibilty option.

\subsection{Energy management and power grid}

The energy management serves as a superordinate control system of the power flows between the individual models on the farm and provides the interface to the power grid. The control process aims to maximise the internal consumption of the energy generated by the renewable energies and thus reduce the amount of energy supplied by the grid.

The grid calculation is carried out with the help of MATPOWER [7]. MATPOWER calculates the power flow with the grid structure and generator and consumption power as input data. The grid results can then be analysed and visualised in MATLAB and required and suitable grid optimisation and reinforcement measures can be determined.

\section{Simulation environment}

The modelling of the technical components (Chapter 2) and the simulation studies (Chapter 4) are carried out in the institute's simulation environment eSE (elenia Simulation Environment) [8]. eSE is a MATLAB-based simulation environment for the scientific investigation 
of electrical and thermal systems and their behavior. In addition, a flexible signal coupling of individual devices enables the investigation of connected systems and the testing of control concepts.

The simulation environment is divided into different modules, which can be used independently or in combination. The connection between all modules is the Simulator, which is represented by a single MATLAB class. It controls the information flow between the modules and takes over the central data management. The result of a simulation is a collection of time series of individual information flows and physical parameters of the devices, which can then be analyzed and evaluated. Figure 7 shows the three pathes of the simulation process in eSE.

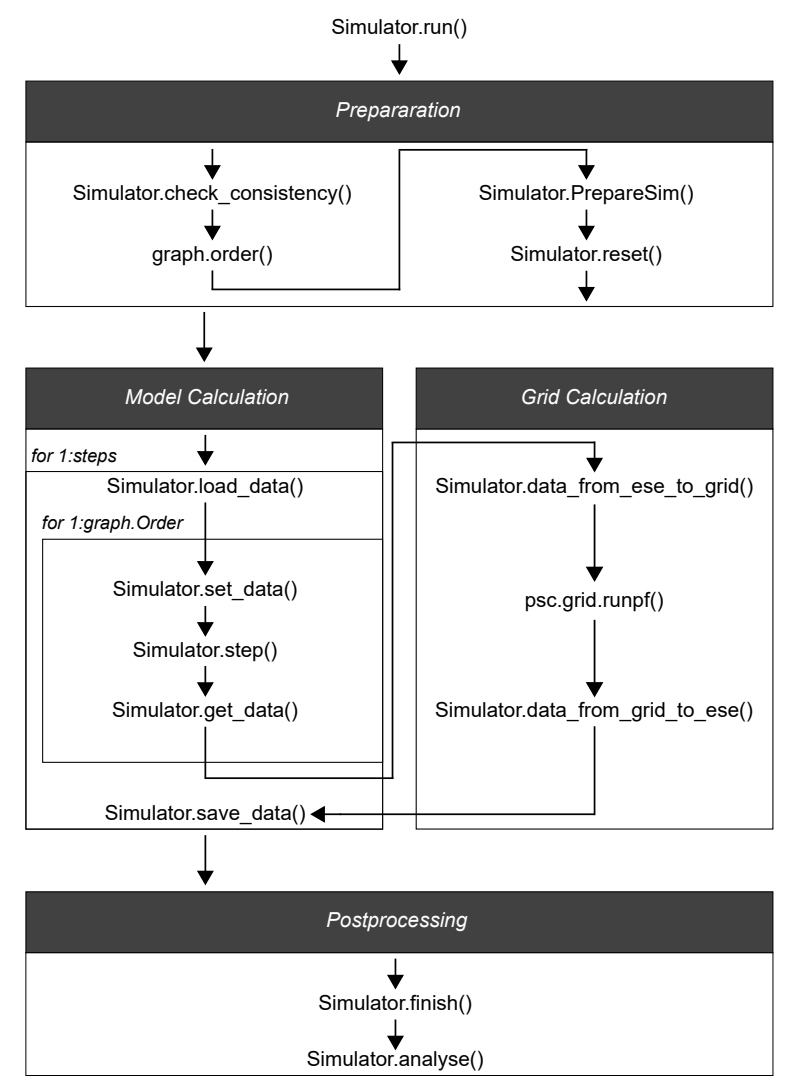

Figure 7: Simulation process in eSE

In the preparation step, the simulation is checked for consistency and possible errors and automatically repaired if necessary. Afterwards a directed graph is created, which indicates the simulation order of the models by means of a topological search algorithm. Before all models are reset to a valid initial state, the simulation is prepared. During the preparation, model relationships are stored temporarily in a local data structure to avoid database queries during the simulation.

At the beginning of each simulation step, stored external data sets are reloaded from an HDF5 file. Subsequently, three methods are executed for each model step. Before the model calculation, data from other models or external data sets are assigned to the model. Then the model with the functional relationships is calculated and result values are queried afterwards. The result values for active and reactive power are used as input values for the grid calculation to perform the load flow calculation with MATPOWER. The resulting values of the grid resources are finally queried and stored together with the model results in the HDF5 file for time series.

In the final phase, defined key indicators of time series and model properties are calculated and stored in an SQLite database. In addition, economic calculations of stakeholders and models are executed.

\section{Simulation scenarios and results}

To assess the power grid integration for all-electric agricultural machines, several simulation scenarios are considered and compared with each other. The simulation scenarios differ according to the power grid connection level of the agricultural enterprise (low voltage or medium voltage) and the selected charging strategy (Charging with minimum power, Charging with maximum power), resulting in four simulation scenarios. Due to the differentiation at the power grid connection level, different compositions of renewable energies are considered for the scenarios. The selected parameterization is shown in Table 1.

\begin{tabular}{c|c|c}
\hline Model & $\begin{array}{c}\text { Low voltage } \\
\text { scenarios }\end{array}$ & $\begin{array}{c}\text { Medium voltage } \\
\text { scenarios }\end{array}$ \\
\hline Photovoltaic plant & $30 \mathrm{~kW}$ & $100 \mathrm{~kW}$ \\
\hline Wind power plant & - & $100 \mathrm{~kW}$ \\
\hline Biogas plant & - & $75 \mathrm{~kW}$ \\
\hline Charging Station & $50 \mathrm{~kW}$ & $300 \mathrm{~kW}$ \\
\hline $\begin{array}{c}\text { Battery-powered } \\
\text { machines }\end{array}$ & $\begin{array}{c}1 \times 260 \mathrm{kWh} \\
1 \times 600 \mathrm{kWh}\end{array}$ & $\begin{array}{c}1 \times 260 \mathrm{kWh} \\
1 \times 600 \mathrm{kWh}\end{array}$ \\
\hline $\begin{array}{c}\text { Grid-connected } \\
\text { machines }\end{array}$ & 2 & 2 \\
\hline
\end{tabular}

Table 1: Parameterization of the simulation scenarios 
For all scenarios, four all-electric agricultural machines are considered, whereby two are battery-powered with built-in batteries (used in fertilization, sowing and harvest) and two are grid-connected (used in soil tillage and harvest). The inclusion of four agricultural machines in the scenario enables a realistic representation of agricultural machines needed for a typical process chain in field cultivation. The battery-powered agricultural machines can be recharged after completion of the field cultivation at one charging station. A realistic annual load profile from a measurement campaign on a dairy farm with 120 cows is used as base load to model the remaining electricity consumption of the agricultural operation [9].

The low voltage distribution grid is represented by Kerber's Landnetz Kabel 1 benchmark power grid and supplies five agricultural operations and three households [10]. The medium voltage distribution grid used is the CIGRE benchmark grid, where at load nodes 8 and 11 an agricultural operations is considered [11]. The remaining load nodes are mapped with standard load profiles for households and businesses [12].

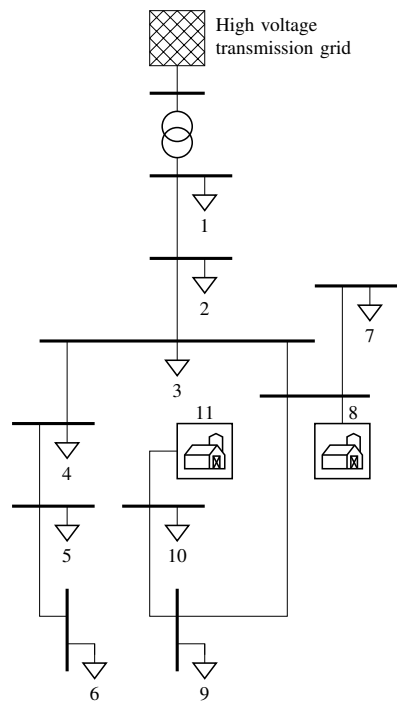

Medium voltage distribution grid
Low voltage distribution grid

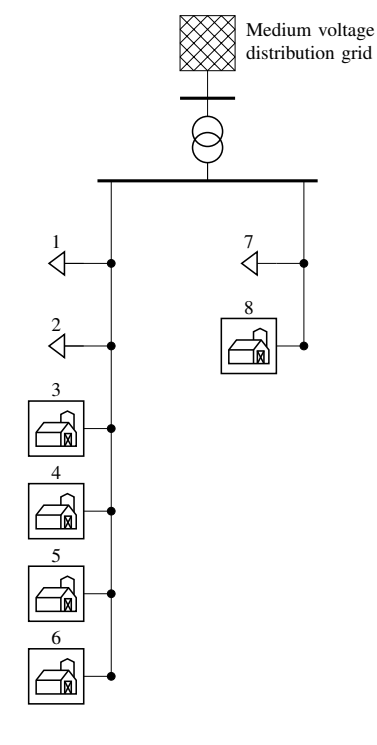

Figure 8: Structure of the modelled distribution grids

The simulation is carried out using nine randomly selected type days distributed over an entire year, which allows seasonally dependent fluctuations in generation and consumption to be depicted and meaningful results to be obtained for the entire year. The type days cover arbitrarily selected agricultural processes with each agricultural machine being used at least once. The

\begin{tabular}{c|c|c|c}
\hline Season & Day & $\begin{array}{c}\text { Frequency } \\
\text { per year }\end{array}$ & $\begin{array}{c}\text { Agricultural } \\
\text { process }\end{array}$ \\
\hline \multirow{3}{*}{ Winter } & 13.03. & 100 & Fertilization \\
& 23.11. & 20 & - \\
& 03.02 & 20 & Plant protection \\
\hline \multirow{5}{*}{ Summer } & 14.08. & 88 & Harvest \\
& 03.08. & 18 & Soil tillage \\
& 26.05. & 17 & - \\
\hline \multirow{3}{*}{ Transition } & 09.04. & 73 & - \\
& 20.04. & 14 & Fertilization \\
& 15.09. & 15 & Sowing \\
\hline
\end{tabular}

Table 2: Chosen type days for the simulation

frequency of the type days does not necessarily correspond to the whole duration of the agricultural processes, but since the agricultural machines are mostly used for further agricultural work, the selection of processes and allocation to the type days is assumed to be sufficiently accurate.

\subsection{Technical results}

The simulated agricultural operation with low voltage power grid connection shows an average own consumption of $39 \%$ and an average self-sufficiency of $17 \%$ when using the charging strategy Charging with maximum power. On days without the use of all-electric

\begin{tabular}{l|l|l}
\hline & $\begin{array}{l}\text { Charging } \\
\text { max. Power }\end{array}$ & $\begin{array}{l}\text { Charging } \\
\text { min. Power }\end{array}$ \\
\hline Own consumption & $39 \%$ & $39 \% \Rightarrow$ \\
\hline Self-sufficiency & $17 \%$ & $18 \%$ \\
\hline max. power grid supply & $212 \mathrm{~kW}$ & $188 \mathrm{~kW}$ \\
\hline max. power grid feed-in & $22 \mathrm{~kW}$ & $22 \mathrm{~kW} \Rightarrow$ \\
\hline
\end{tabular}

Table 3: Technical results for the agricultural operations with low voltage power grid connection

agricultural machines, but with a high level of renewable energy production, there are feed-in capacities of up to a maximum of $22 \mathrm{~kW}$. On days with usage of all-electric agricultural machines and low regenerative energy production, a grid supply of up to $212 \mathrm{~kW}$ is required. By using the charging strategy Charging with minimum power, the own consumption and selfsufficiency do not increase significantly, as the charging 
times of the battery-powered agricultural machines are outside the generation times of the photovoltaic plant for both charging strategies.

\begin{tabular}{l|l|l}
\hline & $\begin{array}{l}\text { Charging } \\
\text { max. Power }\end{array}$ & $\begin{array}{l}\text { Charging } \\
\text { min. Power }\end{array}$ \\
\hline Own consumption & $17 \%$ & $18 \% \Rightarrow$ \\
\hline Self-sufficiency & $70 \%$ & $98 \%$ \\
\hline max. power grid supply & $233 \mathrm{~kW}$ & $123 \mathrm{~kW}$ \\
\hline max. power grid feed-in & $178 \mathrm{~kW}$ & $178 \mathrm{~kW}$ \\
\hline
\end{tabular}

Table 4: Technical results for the agricultural operations with medium voltage power grid connection

In the two scenarios with grid connection to the medium voltage distribution grid, the degree of self-sufficiency can be significantly increased, which can be attributed to the additional consideration of a biogas plant and wind power plant and the increased nominal capacity of the photovoltaic plant. Using the charging strategy Charging with minimum power instead of Charging with maximum power, the degree of self-sufficiency can be increased to nearly $100 \%$, since the generation capacity of the biogas plant and wind power plant can cover the entire consumption capacity more frequently (cf. Figure 9).

For the scenarios considered, possible voltage band violations and thermal overloads in the power grid are examined. The voltage applied to the network nodes in the power grid changes depending on the connected loads, generation plants and the location in the power grid. The permitted deviations from the nominal voltage are defined in DIN EN 50160 [13].

The thermal load capacity of the power grid elements used is regarded as a further key figure for determining the condition of the power grid. The nominal load capacity of the equipment is often specified in the associated data sheets and is assumed to be the limit value in the following.

\begin{tabular}{l|l|l}
\hline & $\begin{array}{l}\text { Charging } \\
\text { max. Power }\end{array}$ & $\begin{array}{l}\text { Charging } \\
\text { min. Power }\end{array}$ \\
\hline Voltage range deviations & $18 \%$ & $18 \% \Rightarrow$ \\
\hline Thermal overload & $21 \%$ & $18 \%$ \\
\hline
\end{tabular}

Table 5: Frequency of limit violations in the low voltage power grid per year

Table 5 shows the results for the low voltage distribution
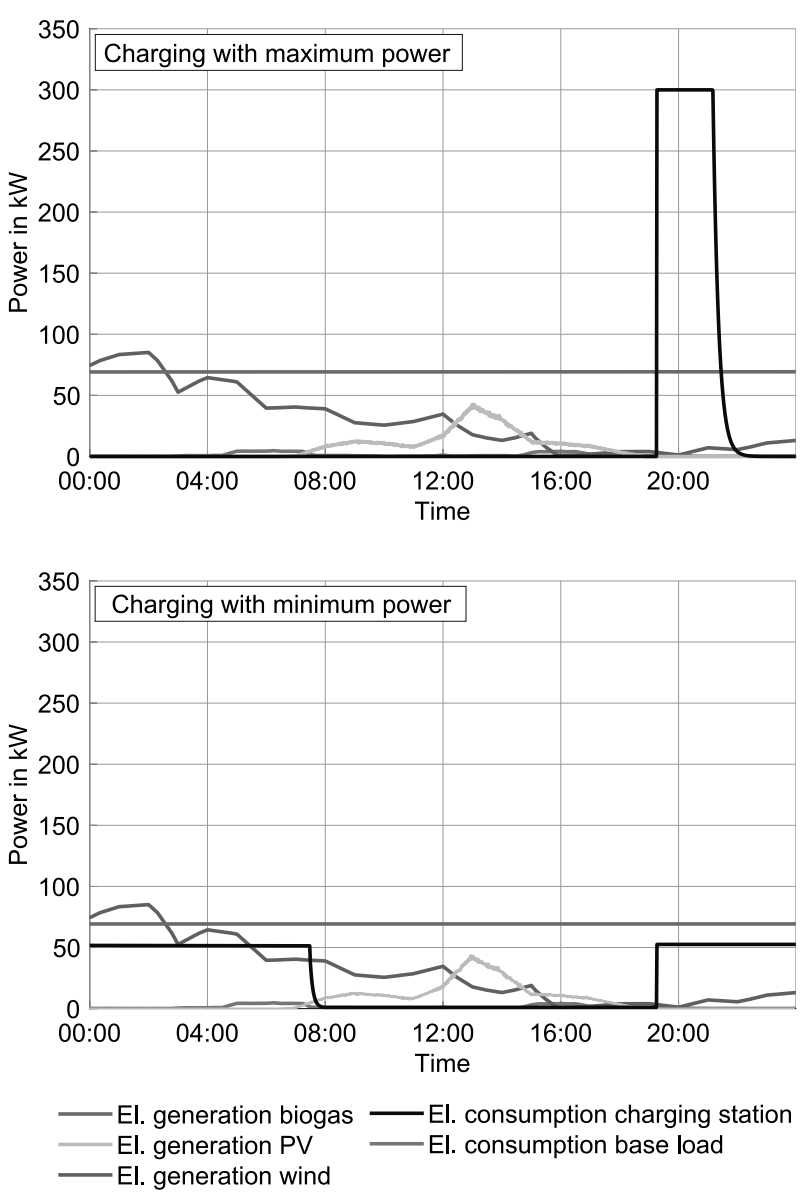

Figure 9: Electrical generation and consumption of different models on 15 . September during sowing

grid. In both scenarios with connection to the low voltage distribution grid, voltage band violations and equipment overloads occur on almost every power grid element, whereby the frequency of equipment overloads per year is slightly reduced by using the charging strategy Charging with minimum power compared to Charging with maximum power. Due to the limit value violations in the low voltage power grid and the maximum power grid supply of the individual agricultural operations, it can be useful to change the grid connection level of these operations to medium voltage. The medium voltage distribution grid did not show any limit value violations in the two scenarios with connection to the medium voltage distribution grid and is therefore suitable for agricultural operations with a previous connection to the low voltage distribution grid as a possible grid integration solution for all-electric agricultural machines. 


\section{Conclusion and future plans}

This paper describes preliminary studies for the research project "Concept and modeling of agricultural systems with renewable energy supply - Energy-4Agri”. The development and evaluation of energy supply concepts for all-electric agricultural machines requires a holistic modelling of the involved technologies. This paper therefore provides information on the modelling and simulation of the technologies and energy systems.

Diesel consumption profiles were chosen as input data set for the all-electric agricultural machines. The conversion to electric power values can only be seen as a first approximation given a dynamic efficiency of combustion engines. Further research is therefore needed in the development of electric power profiles for all-electric agricultural machines, which take into account dynamic efficiency of the internal combustion engine and can thus provide more accurate simulation results. It has been shown that the charging strategy Charging with minimum power can already reduce the grid load in contrast to Charging with maximum power and increase the degree of self-sufficiency. In the future, further charging strategies can be modelled to determine the optimal charging times based on forecast data of the generation capacities of the renewable energies or depending on the power grid condition.

\section{Acknowledgement}

The work of this paper is originally based on the research project "Energy-4-Agri" (FKZ 03EI1013A). The authors acknowledge the support of the project within the energy research programme of the Federal Ministry of Economics and Energy and the Projektträger Jülich. The responsibility for the content of this publication lies with the authors and does not necessarily reflect the opinion of the project consortium Energy-4-Agri.

Supported by:

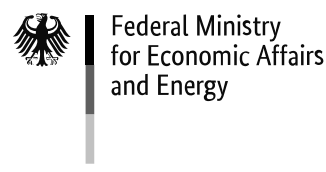

on the basis of a decision by the German Bundestag

\section{References}

[1] Frerichs L, Hanke S, Steinhaus S, Trösken L. EKoTech - A Holistic Approach to Reduce CO2 Emissions of Agricultural Machinery in Process Chains. In: 9th AVL International Commercial Powertrain Conference 2017, edited by SAE Mobilus, SAE Technical Paper Series. SAE International. 2017; .

[2] Diekmann S, Reinhold C, Engel B. Centralized energy management for the optimization of residential districts. In: International ETG Congress 2017. ETG, Berlin and Offenbach: VDE Verlag GmbH. 2017; .

[3] Ortsgenaue Testreferenzjahre von Deutschland für mittlere, extreme und zukünftige Witterungsverhältnisse. Offenbach: Deutscher Wetterdienst and Bundesamt für Bauwesen und Raumordnung. 2017.

[4] Erichsen G. DWD weather model data for energy system simuation: 2017. 2020.

[5] NPS 100C-24: Datasheet. Northern Power Systems.

[6] Sonstige Marktregeln Strom: Kapitel 6: Zählwerte, Datenformate und standardisierte Lastprofile. Österreich: E-Control. 2015.

[7] Zimmermann R, Murillo-Sanchez C, Thomas R. MATPOWER: Steady-State Operations, Planning and Analysis Tool for Power Systems Research and Education. Power Systems, IEEE Transactions on. 2011;26(1):12-19.

[8] Reinhold C, Engel B. Simulation environment for investigations of energy flows in residential districts and energy management systems. In: International ETG Congress 2017. ETG, Berlin and Offenbach: VDE Verlag GmbH. 2017; .

[9] Neiber J. Strombedarf und Eigenstromversorgung in der Nutztierhaltung. Mannheim. 2020.

[10] Kerber G. Aufnahmefaehigkeit von Niederspannungsverteilnetzen fuer die Einspeisung aus Photovoltaikkleinanlagen. Dissertation, Technische Universitaet Muenchen, Muenchen. 2010.

[11] Rudion K, Orths A, Styczynski ZA, Strunz K. Design of benchmark of medium voltage distribution network for investigation of DG integration. In: IEEE Power Engineering Society general meeting, 2006. IEEE, Canada: IEEE Operations Center. 2006; .

[12] Meier H, Fünfgeld C, Adam T, Schieferdecker B. Repräsentative VDEW-Lastprofile. Frankfurt am Main: VDEW. 1999.

[13] DKE Deutsche Kommission Elektrotechnik Elektronik Informationstechnik in DIN und VDE. Voltage characteristics of electricity supplied by public distribution networks. 50160. Berlin: Beuth Verlag GmbH. 2010. 